\title{
Search method of the parameters network elements based on three-dimensional calculations
}

\author{
Dmitry V. Boykov ${ }^{2, *}$, and Aleksandr A. Dekterev ${ }^{1,2}$ \\ ${ }^{1}$ Kutateladze Institute of Thermophysics SB RAS, Novosibirsk, Russia \\ ${ }^{2}$ Siberian Federal University, Krasnoyarsk, Russia
}

\begin{abstract}
The paper proposes a method to identify a pipeline system segment, containing several piping assemblies and branches, based on threedimensional calculations or experiments, as well as proves the applicability of proposed approach to search the local resistance coefficients of the section elements of the pipeline system, which describes the complex spatial structure, based on the known values of pressure drops and flow rates.
\end{abstract}

\section{Introduction}

Practically each industrial enterprise has one or another pipeline system in which gas or liquid flow distribution essentially influence technical, economic, and ecological characteristics of production in general. In some cases, objects under study can be represented as a hydraulic network [1]. The network may contain structural elements, whose local resistance significantly affects the nature of flow distribution. Sometimes, determining the resistance coefficients of these elements by existing empirical and analytical dependencies[2,3] is impossible.

Applying spatial simulation $[4,5]$ to these structural elements allows defining hydraulic characteristics and using them in network design model. Earlier, the authors in [6,7] mentioned the difficulty of integrating models with a large number of independent inputs. Building a certain network analog of the element was proposed as one of the possible ways to solve this problem. Although this approach has limited applicability and accuracy as compared to the option with direct integration of the three-dimensional element into the network model [8], it allows quickly constructing the hydraulic network model and obtaining the results of calculations.

As an example of the use of proposed approach, the authors consider the problem on simulation of a multi-tiered scrubber (Fig.1). Scrubber is a complex object with five independent inlets. Using a full spatial model or hybrid model with directly embedded threedimensional element into a network model $[6,7]$ results in excessive computational costs. The authors used a simplified network model of this object (Fig. 2). To determine the parameters of the network elements, several three-dimensional calculations were carried out.

* Corresponding author: dimkadim@yandex.ru 
In consequence of these calculations, knowing flow rates at the inlet, we determined pressure drops between the scrubber inlets and outlets (Table. 1).
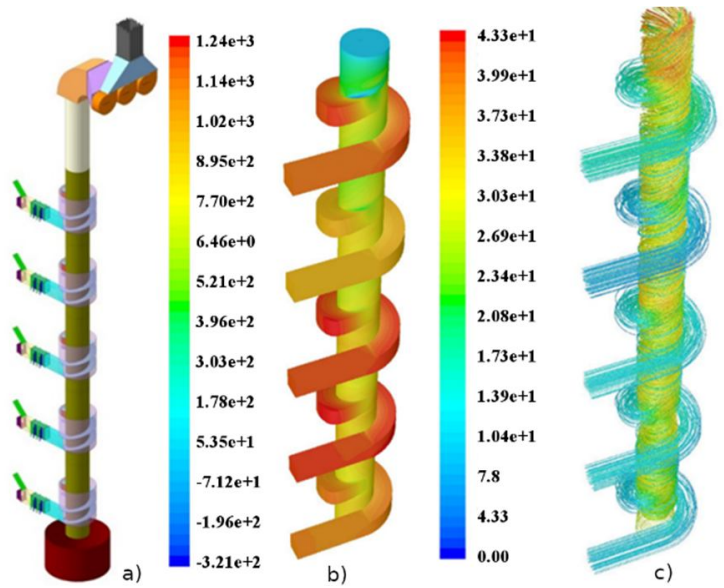

Fig. 1. Scrubber: a) geometry; b) static pressure $(\mathrm{Pa})$; c) streamlines.

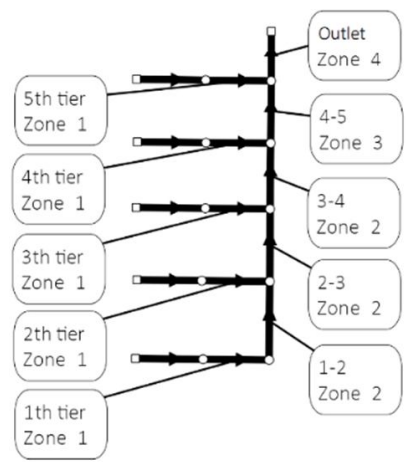

Fig. 2. Network model of scrubber.

The network analogue of the spatial scrubber model (Fig. 2) was divided into several zones:

1. the zone of all inlets, whose geometric similarity suggests the existence of a single local resistance coefficient at all sites in the zone;

2. the zone of a lifting pipe from the $1^{\text {st }}$ to $4^{\text {th }}$ tier, where small velocities allowed suggesting that the influence of the local resistance of these tiers on the flow distribution in the scrubber will be insignificant and, accordingly, local resistance was set to 0 for all sections of the zone;

3. the zone of a lifting pipe from the $4^{\text {th }}$ to $5^{\text {th }}$ tier;

4. the zone of access to the fan.

Accordingly, the problem was reduced to finding three local resistance coefficients for zones 1, 3 and 4 satisfying the condition of minimum difference between the pressure drop in the scrubber for network computations and 3D calculations. Initially, the coefficients were found by the exhaustive search method [6,7]. Unfortunately, such a search method becomes too expensive at a large number of unknown parameters. In this regard, it turned out to be advisable developing a search algorithm to find parameters of the network section based on known data from the results of $3 \mathrm{D}$ calculation or experiment. 
Table 1. Calculation data of scrubber 3D model

\begin{tabular}{|c|c|c|c|c|c|c|}
\hline \multirow{2}{*}{} & \multicolumn{2}{|c|}{$\mathbf{1}^{\text {st }}$ 3D calculation } & \multicolumn{2}{c|}{$\mathbf{2}^{\text {nd }}$ 3D calculation } & \multicolumn{2}{c|}{$\mathbf{3}^{\text {rd }}$ 3D calculation } \\
\cline { 2 - 7 } & $\begin{array}{c}\text { Pressure, } \\
\mathbf{P a}\end{array}$ & $\begin{array}{c}\text { Flow rate, } \\
\mathbf{k g} / \mathbf{s}\end{array}$ & $\begin{array}{c}\text { Pressure, } \\
\mathbf{P a}\end{array}$ & $\begin{array}{c}\text { Flow rate, } \\
\mathrm{kg} / \mathrm{s}\end{array}$ & $\begin{array}{c}\text { Pressure, } \\
\mathbf{P a}\end{array}$ & $\begin{array}{c}\text { Flow rate, } \\
\mathbf{k g} / \mathbf{s}\end{array}$ \\
\hline $\mathbf{1}^{\text {st }}$ tier & 799 & 6.60 & 2712 & 13.20 & 555 & 6.60 \\
\hline $\mathbf{2}^{\text {nd }}$ tier & 952 & 7.80 & 2019 & 7.80 & 210 & 0.10 \\
\hline $\mathbf{3}^{\text {rd }}$ tier & 950 & 8.12 & 3263 & 16.30 & 196 & 0.10 \\
\hline $\mathbf{4}^{\text {th }}$ tier & 656 & 5.14 & 1529 & 5.14 & 383 & 5.14 \\
\hline $\mathbf{5}^{\text {th }}$ tier & 934 & 9.86 & 1566 & 9.86 & 836 & 9.86 \\
\hline Outlet & 0 & 37.52 & 0 & 52.27 & 0 & 21.80 \\
\hline
\end{tabular}

\section{Flue ducting calculation model}

As a mathematical model to describe the fluid flow in the network, a model of steady-state flow of incompressible fluid was adopted. For representation of pipeline system we use the directed graph[9], whose constraint matrix is presented in the following form:

$$
\nabla_{i l}=\left\{\begin{array}{c}
1, \text { if } l \in O_{i}, \\
-1, \text { if } l \in I_{i}, \\
0 \quad \text { otherwise }
\end{array}\right.
$$

where $l \in O_{i}$ - is the plurality of pipes coming out from the $i$-th piping assembly; $l \in I_{i}-$ is the plurality of pipes going into the $i$-th piping assembly. The problem of flow distribution in the network can be reduced to a combination of the mass conservation law in the piping assembly (2), and the flow resistance law in the pipe (3):

$$
\begin{gathered}
\sum_{l \in U_{j}} \nabla_{j l} x_{l}=0 \\
\sum_{i \in N} \nabla_{i l} p_{i}=h_{l}\left(x_{l}\right)
\end{gathered}
$$

where $N$ - is the set of all network piping assemblies; $U$ - is the set of all network branches; $x_{l}-$ is the flow rate in the branch $(\mathrm{kg} / \mathrm{s}) ; h_{l}\left(x_{l}\right)$ - is the pressure loss $(\mathrm{Pa}) ; \mathrm{p}-$ is the pressure $(\mathrm{Pa})$.

Finding a solution to this nonlinear system of equations is carried out by the nodal pressure method. That is, the following flow rate and pressure is sought through the correction:

$$
\begin{aligned}
& x_{l}^{K+1}=x_{l}^{K}+\delta x_{l} \\
& p_{i}^{K+1}=p_{i}^{K}+\delta p_{i}
\end{aligned}
$$

Substituting equations (4) and (5) in (2) and (3) it is easy obtaining a system of linear algebraic equations (SLAE) for the pressure correction:

$$
\begin{gathered}
\sum_{i \in N} \Delta_{i j}(a) \delta p_{i}=-\sum_{l \in U_{j}} \nabla_{i l} x_{l}, j \in N_{\text {inner }} \\
\delta p_{j}=0, j \in N_{b d r}
\end{gathered}
$$




$$
\begin{gathered}
\Delta_{i i}(a)=\sum_{l \in U_{l}} a_{l}, i \in N_{\text {inner }} \\
\Delta_{i j}(a)=-\sum_{l \in U_{l}} a_{l}, i \in N_{\text {inner }}, j \in N, i \neq j \\
a_{l}=\left\{\begin{array}{c}
\left(\frac{\partial h_{l}}{\partial x_{l}}\right)^{-1}, l \in U_{\text {inner }} \\
0, l \in U_{b d r}
\end{array}\right.
\end{gathered}
$$

here $N_{b d r}, N_{\text {inner }}$ - are sets of boundary nodes and computational nodes, respectively; $U_{b d r}, U_{\text {inner }}$ - are sets of boundary branches and computational branches, respectively. Pressure is fixed in the boundary nodes, while flow rate is fixed in the boundary branches.

\section{Search for local resistance coefficients}

For the identified branches, we determine the correction of the analyzed value in the form of [10]:

$$
C^{K+1}=C^{K}+d C
$$

where $C$ can be, for example, diameter or local resistance.

Substituting (5) and (7) in (2) and (3) we obtain SLAE, which associates the correction of some magnitude in the branches with the resulting pressure change in the nodes.

$$
\begin{gathered}
\sum_{i \in N} \Delta_{i j}(a) d p_{i}=\sum_{l \in U} \nabla_{i l}\left(\frac{\partial h_{l}}{\partial x_{l}}\right)^{-1}\left(\frac{\partial h_{l}}{\partial C}\right) d C, j \in N_{\text {inner }} \\
d p_{j}=0, j \in N_{b d r}
\end{gathered}
$$

Where $d p_{i}$ - is the pressure change; $d C$ - is the correction. The left part of equation (6) at the final iteration coincides with the left part of the SLAE of the correction (8).

It is easy to show that the resulting pressure change for the sum of the different impacts is equal to the sum of the pressure changes of these impacts. Using the computation results of the SLAE (8) this allows determining the SLAE for correction of the variable:

$$
\frac{d p_{I}^{m}}{d C_{m}} \cdot \delta C_{m}=P_{I}-p_{I}, m \in U_{\text {ident }}, I \in M_{\text {control }}
$$

here $\delta C_{m}$ - is the correction of the identified value, $m \in U_{\text {ident }}-$ is the set of identifiable objects, $P_{I}^{m}$ - is the required pressure in the control points, $p_{I}^{m}$ - is the pressure in the specified nodes (control points) of the network model for which the model is adapted, $I \in M_{\text {control }}$ - is the set of control points.

The coefficient $d p^{m}{ }_{I} / d C_{m}$ is defined as the ratio of pressure change in the control node $d p_{I}$ to the corresponding change of the identified value $d C_{m}$ and is found through the solution of the equations system (8) for all options of control actions. The object being identified can be understood as both a single branch and a group of similar branches (by example 1, Fig. 2).

In this example, the control points are the inlets to the scrubber (Table 1). The required pressure $P_{I}$ is taken from the corresponding 3D calculation (three 3D calculations, 5 nodes in each, 15 calculation points in total). The resulting system of equations is over-defined [11]. A fixed flow rate is given on boundary branches. 
The coefficient of local resistance in the formula for pressure loss is the identifiable value: $h_{l}\left(x_{l}, \xi_{m}\right)=\xi_{m} \frac{\left|x_{l}\right| \cdot x_{l}}{2 \cdot \rho_{l} \cdot s_{l}{ }^{2}}$ where $\xi_{m}-$ is the local resistance coefficient; $s_{l}-$ is the crosssectional area of the pipeline $\left(\mathrm{m}^{2}\right)$, and $\rho_{l}-$ is the flow density $\left(\mathrm{kg} / \mathrm{m}^{3}\right)$. The right part of SLAE (8) can be represented as:

$$
\left(\frac{\partial h_{l}}{\partial x_{l}}\right)^{-1}\left(\frac{\partial h_{l}}{\partial \xi_{m}}\right) d \xi_{m}=\frac{x_{l}}{2 \xi_{m}} d \xi_{m}
$$

The above allows proposing the following algorithm for searching the local resistance of identifiable branches: The network model $(2,3)$ is calculated for each three-dimensional calculation, in which the flow rate is fixed at the boundary branches. To calculate matrix columns $d p^{m}{ }_{I} / d C_{m}$, SLAE (8) is solved for each three-dimensional calculation and for each identifiable object. New local resistance coefficients are calculated after solving resulting SLAE (9), after which the cycle repeats over again.

\section{The result of solving the test task}

Table 2. The local resistance coefficient

\begin{tabular}{|c|c|c|c|c|}
\hline & $\begin{array}{c}\text { Search } \\
\text { method }\end{array}$ & Option 1 & Option 2 & Option 3 \\
\hline $1^{\text {st }}$ tier & 2.8 & 2.4 & 2.5 & 2.7 \\
\hline $2^{\text {nd }}$ tier & 2.8 & 2.0 & 2.5 & 2.7 \\
\hline $3^{\text {rd }}$ tier & 2.8 & 2.3 & 2.5 & 2.7 \\
\hline $4^{\text {th }}$ tier & 2.8 & 2.2 & 2.5 & 2.7 \\
\hline $5^{\text {th }}$ tier & 2.8 & 2.6 & 2.5 & 2.7 \\
\hline $1^{\text {st }}$ and $2^{\text {nd }}$ tiers & 0 & 0 & 1.8 & 0 \\
\hline $2^{\text {nd }}$ and $3^{\text {rd }}$ tiers & 0 & 0 & 0 & 0 \\
\hline $3^{\text {rd }}$ and $4^{\text {th }}$ tiers & 0 & 1.5 & 1.2 & 0 \\
\hline $4^{\text {th }}$ and $5^{\text {th }}$ tiers & 2.8 & 2.1 & 1.8 & 2.5 \\
\hline Outlet & 2 & 2.2 & 2.3 & 2.1 \\
\hline
\end{tabular}

The proposed algorithm was applied to calculate the multi-tier scrubber. Three grouping options of local resistance coefficients were considered: 1 - all branches are considered to be independent; 2 - inlets at tiers are united into a single block (zone 1 in Fig. 2); and 3 - the option fully corresponds to the problem statement as in the exhaustive search method. Table 2 shows the local resistance coefficients for all three options. The exhaustive search method and the method proposed in option 3 gave similar results.

Table 3 shows the comparison of the models with respect to the pressure drop. In all options, pressure drops are close to the data obtained through 3D modeling, while the error does not exceed the accuracy of calculations accepted for engineering practice.

\section{Conclusion}

We proposed a method for determining the parameters of the network branches based on to the three-dimensional calculation. The local resistance coefficients of several branches of the network model based on the spatial simulation are determined on the example of calculations of a multi-tier scrubber. 
Table 3. Comparison of network models

\begin{tabular}{|c|c|c|c|c|c|}
\hline \multicolumn{3}{|c|}{ No. of 3D caculation } & \multicolumn{3}{|c|}{ 1st calculation } \\
\hline & $\begin{array}{c}\text { 3D } \\
\text { calculation }\end{array}$ & $\begin{array}{c}\text { Exhaustive } \\
\text { search method }\end{array}$ & Option 1 & Option 2 & Option 3 \\
\hline $1^{\text {st }}$ tier & 799 & 990 & 1003 & 995 & 966 \\
\hline $2^{\text {nd }}$ tier & 952 & 1118 & 1053 & 1095 & 1086 \\
\hline $3^{\text {rd }}$ tier & 950 & 1154 & 1113 & 1127 & 1121 \\
\hline $4^{\text {th }}$ tier & 656 & 854 & 778 & 788 & 837 \\
\hline $5^{\text {th }}$ tier & 934 & 1087 & 1003 & 1059 & 1076 \\
\hline \multicolumn{3}{|c|}{ No. of 3D calculation } & \multicolumn{3}{|c|}{ 2nd calculation } \\
\hline & $\begin{array}{c}\text { 3D } \\
\text { calculation }\end{array}$ & $\begin{array}{c}\text { Exhaustive } \\
\text { search method }\end{array}$ & Option 1 & Option 2 & Option 3 \\
\hline $1^{\text {st }}$ tier & 2712 & 2714 & 2680 & 2678 & 2619 \\
\hline $2^{\text {nd }}$ tier & 2019 & 1817 & 1915 & 1901 & 1819 \\
\hline $3^{\text {rd }}$ tier & 3263 & 3385 & 3215 & 3221 & 3255 \\
\hline $4^{\text {th }}$ tier & 1529 & 1595 & 1454 & 1446 & 1556 \\
\hline $5^{\text {th }}$ tier & 1567 & 1431 & 1459 & 1464 & 1447 \\
\hline \multicolumn{3}{|c|}{ No. of 3D calculation } & \multicolumn{3}{|c|}{ 3rd calculation } \\
\hline & $\begin{array}{c}\text { 3D } \\
\text { calculation }\end{array}$ & $\begin{array}{c}\text { Exhaustive } \\
\text { search method }\end{array}$ & Option 1 & Option 2 & Option 3 \\
\hline $1^{\text {st }}$ tier & 555 & 502 & 460 & 481 & 489 \\
\hline $2^{\text {nd }}$ tier & 210 & 179 & 189 & 188 & 182 \\
\hline $3^{\text {rd }}$ tier & 196 & 178 & 188 & 188 & 181 \\
\hline $4^{\text {th }}$ tier & 383 & 375 & 332 & 351 & 367 \\
\hline $5^{\text {th }}$ tier & 836 & 844 & 800 & 773 & 816 \\
\hline
\end{tabular}

\section{References}

1. A.P. Merenkov, V.Ya. Khasilev Theory of hydraulic circuits. (1985)

2. I. E. Idel'chik, , Handbook of Hydraulic Resistance. (1992)

3. D. S. Miller, Internal flow systems. (1990)

4. J.H. Ferziger, M. Peric, Computational Methods for Fluid Dynamics. (2002)

5. A.A. Dekterev, K.Yu. Litvintsev, A.A. Gavrilov, E.B. Kharlamov, S.A. Filimonov Journal of Siberian Federal University. Engineering \& Technologies, 10(4) (2017)

6. D. V. Boykov, A. A. Dekterev, S. A. Filimonov. Pipeline energy systems. Mathematical and computer technologies of intellectualization., pp 138-151 (2017)

7. D. V. Boykov, S. A. Filimonov, A. A. Dekterev,. Mathematical modeling of pipeline energy systems. Proceedings of the XIV all-Russia Scientific Seminar with International Participation "Mathematical models and methods of analysis and optimal synthesis of developing pipeline and hydraulic systems" pp. 28-43 (2014)

8. S.A. Filimonov, E.I. Mikhienkova, A.A. Dekterev, D.V. Boykov, Journal of Physics: Conference Series, Vol 899 (2017)

9. $\quad R$. Wilson. Introduction to graph theory (1996)

10. S.P. Epifanov, N.N. Novitsky. Pipeline energy systems. Methods of mathematical modeling and optimization. pp 27-47 (2007)

11. Benoît Jacob, Gaël Guennebaud. Eigen 3 documentation 